\title{
A taxonomic review of Neogriphoneura Malloch, 1924 (Diptera: Lauxaniidae), with description of three new species
}

\author{
RAMON LUCIANO DE MELLO ${ }^{1} \&$ VERA CRISTINA SILVA ${ }^{2}$ \\ ${ }^{1}$ Museu de Zoologia da Universidade de São Paulo - USP; Avenida Nazaré, 481; 04263-000, São Paulo, SP, Brazil. \\ E-mail: ramonluciano@usp.br \\ ${ }^{2}$ Depto de Ciências Biológicas, Faculdade de Ciências e Letras de Assis - UNESP São Paulo State University; Av. Dom Antonio, \\ 2100; 19.806-900 Assis, SP, Brazil. E-mail:vcsilva@assis.unesp.br
}

\begin{abstract}
The status of the Lauxaniidae genus Rhabdolauxania Hendel, 1925 is reevaluated and is synonymized under Neogriphoneura Malloch, 1924. Three new combinations, N. immaculata (Hendel, 1933), comb. nov., N. laevifrons (Hendel, 1925), comb. nov., and N. schnusei (Hendel, 1925), comb. nov. are proposed. Two lectotypes are designated. Three new species of Neogriphoneura are described: N. bispoi sp. nov., from Santa Catarina, Brazil, N. pacata sp. nov., from La Paz, Bolivia, and N. corrugata sp. nov. from British Virgin Islands. Illustrations of the head, wing, male and female terminalia are provided for the new species. This raises the number of species in the genus from the present five to eleven. A key is provided for the species of the genus.
\end{abstract}

Key words: Diptera; Lauxaniidae; Neogriphoneura; Rhabdolauxania; Neotropical Region; new species; new combination

\section{Introduction}

The genus Neogriphoneura was described by Malloch (in Malloch \& McAtee 1924), who designated Sapromyza sordida Wiedemann as its type-species. There are currently five New World species in the genus: N. sordida (Wiedemann); N. striatifrons Hendel; N. striga Curran; N. tertia Curran and N. timida Curran. N. sordida is the only Nearctic species in the genus, known from the southern and southeastern United States (Virginia south to Florida, and Texas), as well as in Puerto Rico, Jamaica, Nicaragua and Paraguay (Thompson 2005). All other species are exclusively Neotropical in their distribution.

Hendel (1925) described Rhabdolauxania to include $R$. schnusei and R. laevifrons, described by him from Peru and Bolivia, designating $R$. schnusei as the type-species. Malloch (1928) briefly mentioned that there were some differences between the two known species of Rhabdolauxania at that time. Hendel (1933) described R. immaculata from Paraguay. More recently Stuckenberg (1971), in his account of the geographical distribution of the Lauxaniidae, referred to Rhabdolauxania in the Neotropics and Neogriphoneura in the Nearctic, observing that species of Neogriphoneura also existed in the Neotropical Region.

Actually the detailed study of the morphology of the species of Rhabdolauxania shows that this genus has no substantial differences with respect to Neogriphoneura. All Rhabdolauxania species show the diagnostic features of Neogriphoneura, most strikingly the median longitudinal depression in the anterior part of the frons and the long anterior orbital setae apically incurved. Hendel's (1925) few distinctions for the genus cannot set its species apart from Neogriphoneura. Rhabdolauxania is herein considered a subjective junior new synonym of Neogriphoneura. 